\title{
LANGOS RESPONDS TO SPYROU: CHANGING GROUP NORMS MAY FOSTER POSITIVE RESPONSES TO VICTIMISATION
}

\author{
Colette Langos
}

\section{CONTENTS}

A Cyberbullying, Schools and the Tort of Negligence

B Critique of South Australia's Anti-Bullying Policies

C The Need for Multi-Faceted Responses

D Key Recommendations.

II Changing Class Norms as a Catalyst for Positive Behaviours?.

Thank you to the Editor-in-Chief of the University of South Australia Student Law Review for inviting me to comment on this insightful paper and for giving me the opportunity to contribute to this very special first edition. I would like to begin my 'response' by highlighting how young scholar, Peta Spyrou, the author of the primary article, makes a significant contribution to the existing literature on cyberbullying. The second half of the response includes some 'food for thought' in relation to an issue Spyrou introduces in Part III of her paper, namely, the importance of changing student norms about cyberbullying and victimisation generally. As a researcher who focuses predominantly on evaluating the legal responses to cyberbullying, I often find myself focusing on unscrupulous forms of technological misuse rather than considering novel preventative or 'early intervention' initiatives. This article provides me with an occasion to comment on a discussion of a sociological nature. Let us embrace the value of cross-disciplinary dialogues on an issue which requires cross-sector co-operation to achieve holistic management.

BA, LLB (Adelaide), GDLP (Law Society of South Australia), MComLaw (Deakin), PhD (University of South Australia); Lecturer in law, Law School, University of Adelaide. 


\section{LESSONS LEARNED FROM SPYROU}

\section{A Cyberbullying, Schools and the Tort of Negligence}

There are few scholarly papers which examine the relationship between cyberbullying and the civil law; this paper provides the first comprehensive analysis of how the civil law applies to serious instances of cyberbullying in South Australia. The astute analysis of the interplay between the relevant provisions of the Civil Liability Act 1936 (SA) and the common law provides the reader with clarity on the duty of care that a school owes to its students in instances of bullying, including cyberbullying, both on and off campus. This exposition of the law may serve as a valuable point of reference for policy makers, school authorities and members of the legal profession alike. Discussion of relevant precedent and the inclusion of recent case examples (as reported in the media) may invoke academic dialogue among Australian scholars who examine how the law responds to new technologically driven behaviours.

\section{B Critique of South Australia's Anti-Bullying Policies}

Of significance also, is the originality of the author's research. By exploring how the South Australian Department of Education and Child Development ('DECD') aims to ensure effective implementation of anti-bullying policies (by virtue of the 2014 DECD Improvement and Accountability Policy), notable concerns become apparent. The author's critique of the processes may prompt a review of existing procedures and, further, may prompt similar reviews in other jurisdictions. I would like to acknowledge the significance of the author's qualitative findings; they illuminate how the DECD assesses school anti-bullying policies 'in practice'. Overall, Part II effectively highlights the instrumental role that school authorities play in preventing and managing incidents of cyberbullying to ensure the safety and wellbeing of students in their care (on and off campus).

\section{The Need for Multi-Faceted Responses}

Part III of the primary article highlights the importance of a multi-faceted response strategy (involving schools, parents and bystanders) to managing cyberbullying effectively and comprehensively in the school environment. As cyberbullying is often a relationship problem, the author pertinently comments on the need for schools to foster positive relations between peers and to nurture the sentiment that aggression is unacceptable and 'uncool'. This is an interesting and noteworthy point; one I would like to expand upon briefly below. 


\section{Key Recommendations}

Part III of the primary article extends the arguments made in Part II. Moreover, it provides the reader with recommendations on how the DECD, schools and the wider community need to work together co-operatively to deliver effective management strategies. Recommendations made may contribute to future policy development.

It has been a pleasure to read such an informative paper by an emerging 'cyber-scholar'. The contributions offered are unquestionably significant.

\section{Food For Thought: Class Norms as a CATAlyst For Positive BEHAVIOURS?}

Attitudes and values affect an individual's behaviour and drive responses, both emotional (eg, empathy) and physical (eg, actions). Positive attitudes and respectful behaviour can be nurtured in the school environment in a number of ways, including: teacher based initiatives; wellbeing initiatives (as part of the curriculum); and school policies (eg, implementing behaviour management policies). 'Norms', 1 too, have a profound role to play in shaping how individuals behave in social contexts. Thus, social norms developed in the school (or class) setting affect the way a young person behaves in that environment. Notably, the way that an individual behaves in a group (class or school) may not necessarily reflect an individual's private attitude. ${ }^{2}$ This is often the case in instances of bullying - most students generally disapprove of bullying and sympathise with a victim but do not directly intervene. ${ }^{3}$ This 'inaction' is likely to be explained by the fact that student norms on bullying intervention (actively and openly defending or 'standing up' for a victim) are perceived by the group as a 'risky' behaviour (which could lead to exclusion from the group). Importantly, recent research findings suggest that where a group considers intervention (eg, defending a victim of bullying) to be a class norm, students are more likely to intervene and less likely to watch passively

Norms may be understood as shared expectations about acceptable/unacceptable behaviour in various social contexts. See generally Cristina Bicchieri, The Grammar of Society: The Nature and Dynamics of Social Norms (Cambridge University Press, 2006); Muzafer Sharif, The Psychology of Social Norms (Oxford, 1936).

2 Dorothy Espelage, Melissa Holt and Rachael Henkle, 'Examination of Peer-Group Contextual Effects on Aggression During Early Adolescence' (2003) 73(1) Child Development 205; LR Huesmann and Nancy Guerra, 'Children's Normative Beliefs About Aggression and Aggressive Behaviour' (1997) 72 Journal of Personality and Social Psychology 408.

3 Pozzoli, Tiziana, Gianluca Gini, and Alessio Vieno, 'The Role of Individual Correlates and Class Norms in Defending and Passive Bystanding Behavior in Bullying: A Multilevel Analysis' (2012) 83(6) Child Development 1917, 1918. 
as another student is targeted. ${ }^{4}$ In light of such findings, it is arguable that class norms are powerful catalysts for changing how students view bullying from within the group and, in turn, how students intervene when they witness bullying.

Herein lies an opportunity for future research: what is the most effective way of changing student norms in South Australian primary (and secondary) schools? It would be useful to examine the methods that schools currently employ to encourage positive student norms around bullying prevention and to identify which techniques have particular merit. Once the most effective techniques have been identified, it may be useful for schools to adopt consistent approaches and incorporate them at both the teacher and school policy level. Positive student norms around bullying and bullying intervention (from bystanders) may have a profound effect on student wellbeing where negative group behaviour is minimised. Engaging in initiatives aimed at shifting such norms may be conceived as taking a reasonable precaution against the risk of harm caused by serious instances of bullying. ${ }^{5}$ Schools adopting proactive prevention strategies may be able to better demonstrate that they are fulfilling their duty of care to students. Successfully shifting student norms is unlikely to be achieved via a 'top-down' (zerotolerance) adult control approach (although teachers play a critical role in implementing initiatives which develop student social skills and foster 'provictim' attitudes). Peer-based strategies are more likely to be pivotal since it is young people themselves who are usually in a position to witness and respond. Human behaviour is learnt behaviour ${ }^{6}$ and this means that students who model positive behaviour, such as 'standing up' for those who are targeted, are likely to be instrumental in changing class or group norms.

A further theme for future research involves examining the relationship between social norms and active bystander intervention in instances of cyberbullying. The Australian Human Rights Commission ('AHRC') recently commissioned a study conducted by the Child Health Promotion Research Centre at Edith Cowan University in Western Australia, to identify the most effective strategy to be used in a marketing campaign aimed at encouraging cyberbullying bystanders to take positive action when they witness the conduct. ${ }^{7}$ Findings of the study identified the most effective platforms as being: YouTube videos and trailers; television advertisements; a combined approach using YouTube and television advertisements; Facebook

Ibid.

Civil Liability Act 1935 (SA) s 32.

Albert Bandura, 'Social Learning Theory' (Prentice-Hall, 1977).

Laura Thomas et al, Cyberbullying and the Bystander: Research Findings and Insights Report (2012), 1. 
campaigns; and school-based activities, particularly student presentations. ${ }^{8}$ It is interesting to note that alongside recognising the importance of education initiatives based around digital technologies, young people continue to perceive the school as an important environment for facilitating change in cyberbullying interventions. This response may be driven by young people's understanding that, most of the time, victims of cyberbullying know who the perpetrator is $;^{9}$ and most of the time, cyberbullying can be characterised as a relationship problem between peers in the same social context.

It is posited that initiatives aimed at changing student norms on bystander intervention for cyberbullying ought to occur alongside initiatives focused on traditional bullying. One point to note: cyberbullying bystander intervention is limited to public cyber-forums (where online victimisation can be witnessed). Therefore, the extent to which the bystander can assist in minimising victimisation may be limited (to an extent) in the cyber context. However, since much cyberbullying is motivated by a desire to humiliate a victim publicly, public cyber-forums are the digital platforms where a large percentage of cyberbullying of peers takes place. The significance of shifting norms towards proactive bystander 'defending' is thus paramount. Empowering bystanders to defend those who are targeted may be best achieved through peer-based school initiatives alongside initiatives communicated through digital media.

\section{CONCLUDING REMARKS}

Managing bullying and cyberbullying effectively continues to present schools, law makers, and the community as a whole, with various challenges. Regulatory measures at the school level (school policies) and the state level (criminal and civil laws) are unquestionably important pieces of the matrix, which assist in the minimisation of harm to those who are victimised. Spyrou's primary article provides the reader with much needed insight into the relationship between the civil law and cyberbullying in South Australia; presents the reader with noteworthy critique of current DECD processes surrounding the assessment of school policy implementation; and offers a series of recommendations for co-operative management of cyberbullying

Ibid 3.

Ian Katz et al, Research on youth exposure to, and management of, cyberbullying incidents in Australia: Synthesis report (SPRC Report 16/2014). Sydney: Social Policy Research Centre, UNSW Australia; Jaana Juvonen and Elisheva F Gross, 'Extending the School Grounds?-Bullying Experiences in Cyberspace' (2008) 78(9) Journal of School Health 496. 
(and bullying). Numerous future research opportunities exist in the area of bullying and cyberbullying prevention; this response paper has flagged but two, which build on Spyrou's pertinent observations and follow the theme of changing social norms around bystander intervention in instances of bullying and cyberbullying.

The most rewarding aspect of engaging in research on such a topical issue affecting young Australians is the potential impact new findings can have on their wellbeing. Thank you for your contribution Peta Spyrou. 